\title{
SURGERY OF PEPTIC ULCERATION AND ITS COMPLICATIONS
}

\author{
Norman C. Tanner, M.D., F.R.C.S.
}

\section{Post-Gastrectomy Conditions}

Early post cibal symptoms. I have little to add to the vast amount which has been written on the aetiology of early post cibal symptoms or ' dumping '-that is symptoms of epigastric discomfort, sweating, flushing, palpitation and fatigue, sometimes biliary vomiting, appearing usually shortly after a meal, particularly a heavy meal in patients who have had a gastrectomy. I would, however, suggest that many of the symptoms are merely an exaggeration of the normal physiological response to over-eating. The reaction naturally comes sooner in the gastrectomized, because the capacity for taking food is reduced. Similar symptoms are occasionally encountered in persons who have had no operation, as a form of functional dyspepsia, and they may occur in persons who suddenly take a large meal after many hours or days of frugal meals. In prophylaxis, I commend the practice of explanation before the onset of symptoms. The sudden onset of flushing and palpitation during convalescence shocks the patient and undermines his confidence and leads to apprehension and anxiety. If the patient has been told to expect these symptoms, and reassured that they will progressively diminish and that they do not imply the development of heart or other new trouble - then they are accepted calmly and are minimized rather than exaggerated.

In treatment, the patient should be advised to resume normal meals as early as possible in order to hasten the time when the organism becomes adjusted to the new state of affairs. A period of recumbency should be taken if the symptoms occur, and the tea-time meal-the time when dumping is usually first complained of, should be made a small, dry, high protein, high fat meal-e.g., boiled egg, bread and butter with minimal fluid, or abandoned altogether.

Certain cases are severe enough to require further surgical help. Surgery for post cibal symptoms should not be undertaken less than a year from operation, for the symptoms usually abate with time and they may diminish even as late as after the third or fourth post-operative years. Flushing and palpitations rarely persist and the symptoms most likely to continue are biliary vomiting, which is not always post-prandial, inability to take certain articles of diet with comfort, notably milk or egg, and post-prandial diarrhoea.

We have used six surgical procedures for persistent symptoms.

I. Vagotomy. This was done several years ago in the belief that some of the symptoms might have been due to stimulation of vagus nerve endings in the suture line. This operation has produced no benefit in any case (eight altogether).

2. Short circuiting the afferent and efferent jejunal loops. This is done in the belief that discomfort is due to stasis of bile in the afferent jejunal loop, this belief being supported by the relief often obtained when bile is vomited. As the short circuit reduces the volume of biliary fluid entering the stomach and so increases the risk of stomal ulceration, we usually add a vagotomy. In the earlier four cases a two to three inch long stoma was made, but latterly in two cases we have used Steinberg's pantaloon operation, that is removing the whole spur between efferent and afferent loops right up to the stomach (Fig 16). This operation does diminish biliary vomiting and three of the cases were improved. None were made worse by it.

3. Conversion to a Roux type of stoma. In the Macarthur Lectures which I had the honour to deliver in Edinburgh in 1951 , I mentioned the great benefit to be obtained by conversion to a Roux type of anastomosis when there was severe biliary regurgitation following end in side oesophago-jejunostomy after total gastrectomy (Tanner, I 95 I). I mentioned a simple method of affecting this (Fig. I7). A similar easy method is available following partial gastrectomy, but I pointed out that there was a great risk of stomal 

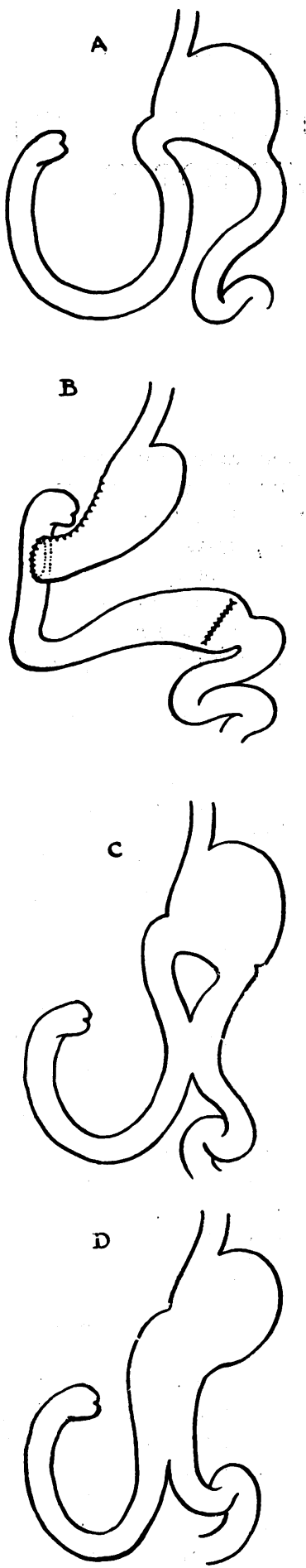

Fig. 16.-Operations designed to correct dumping symptoms. B-Conversion to a gastro-duodenal anastomosis. C-Jejuno-jejunostomy. D-The 'Pantaloon' operation.

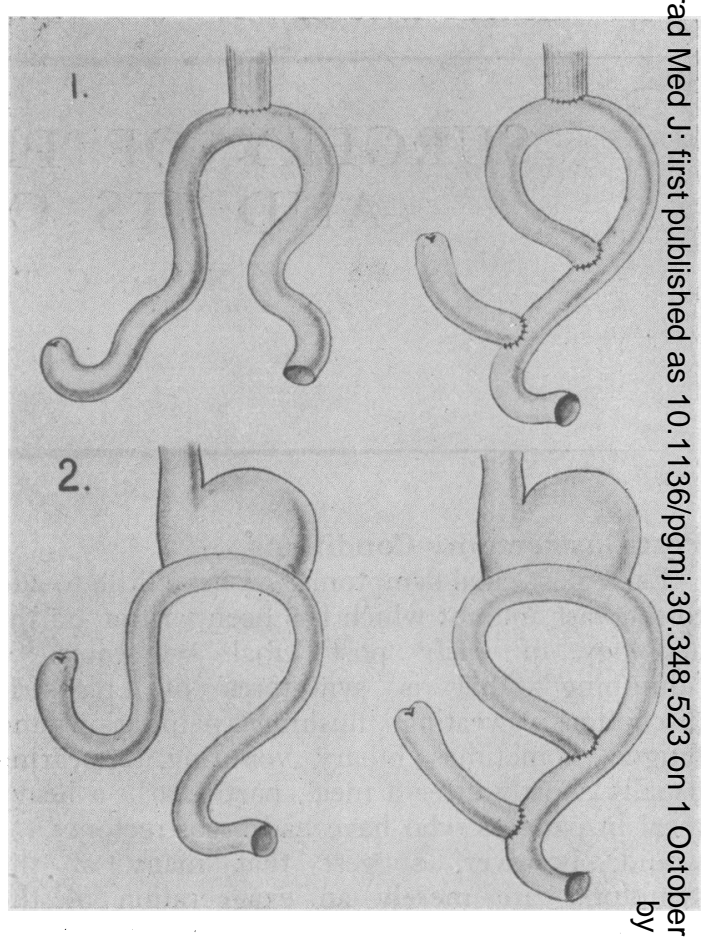

Fig. 17.- Simple methods of conversion of (I) t\&atoror (2) partial gastrectomy to a Roux form of a a astomosis. (Note.-This diagram was also shown in Edin. med. F. article.)

ulceration following and that it must be combiged with vagotomy or a very high partial gastrectogny made. In a partial gastrectomy which I cenverted to a Roux form combined with vagoto ny in 1950, there was no benefit, and I have since converted him to a Billroth I type of anastomasis. My colleague, Mr. Andrew Desmond, did fivo others and there is a suspicion of stomal ulceration in both.

4. Capper and Butler (I95I) suggest that dumping symptoms are due to drag on \&he oesophagus and lesser curve of the stomach by the weight of the filled stomach and adjacent jejungm, and suggest stitching up the gastric stump to the left gastric pedicle and to the gastrosplenic omentum, both as a means of prophylaxis antof treatment. We used it nine times in prophylaxis, and three times in treatment. One of the later had temporary relief but relapsed after fur months, and two had no relief at all. (Kery adequate suspension was later confirmed at a further operation in two cases.) The prophylat tic suspension was added in nine cases. Five ffave no dumping, two have developed mild post cibal symptoms (one with biliary vomiting), one fullness after meals and attacks of diarrhoea find 
Conversion to Billroth I for Dumping

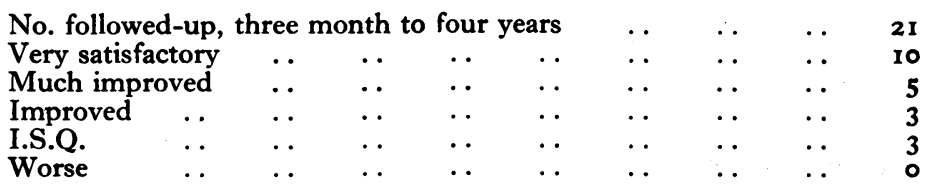

one has late hypoglycaemic-like attacks. These symptoms will probably be transitory, but on the whole, judging by this very small series there is no great improvement

5. Although we found the gastro-duodenal form of anastomosis after gastrectomy to lead to nearly as many cases of dumping as the gastrojejunal anastomosis, they seemed to be less severe forms. Consequently, since 1948 we have tried the effect of conversion from gastro-jejunal to a gastro-duodenal anastomosis in some 26 cases. There was an operative death in a man with mitral stenosis, and one patient died since re turning to his home from pulmonary tuberculosis, from which he was known to have suffered previously. Three have less than three months follow up, leaving 21 cases carried out between three months and four years ago.

The three patients not improved by conversion to a Billroth I anastomosis included one who had previously had a Roux operation, and one patient who was at first remarkably well, now has considerable financial and domestic troubles and relapsed.

This method can be quite dramatic in its good effects. It relieves biliary vomiting and diminishes or abolishes diarrhoea. Some patients who were unable to take milk or egg can now take it with comfort. It is our only present reasonably satisfactory solution to the problem.

6. The last method of treatment is by jejunal or colonic replacement of the stomach. We used the jejunal method with considerable doubt and trepidation in three cases. In two the conversion was carried out for cases of dumping associated with a gastro-jejunal stoma. The operation itself is delightfully simple. Both cases had immediate relief of their symptoms and one remains very well at eight months and has gained eleven pounds in weight. The second began to get severe ulcer pain within six weeks and gastroscopy four months after operation showed extensive jejunal ulceration. At re-operation the replacing loop of jejunum was extensively ulcerated, and so it was removed and a Billroth $I$ form of anastomosis made instead. The patient still remains free of his dumping symptoms and this helps to confirm my belief that the major benefit of jejunal and probably of colonic replacement is the re-direction of gastric chyme through the duodenum. The risk of stomal ulceration is less with colonic replacement, probably because the reverse peristalsis of the colonic loop carries duodenal juices into the stomach. Moroney (195I) has mentioned this point. The jejunal loop might be safer if put in reverse! A third case was one of 'inability to take big meals and loss of weight,' in a woman aged 47. She had already had a high Billroth I anastomosis for gastric ulceration, and this seemed as suitable a case as any for enlarging the stomach by the insertion of a jejunal loop between the stomach and duodenum. She made a good recovery but her symptoms remain quite unchanged.

This small but interesting series of three cases shows that jejunal replacement is easy to do but dangerous in view of the risk of post-operative ulceration. I believe its main benefit is that it returns the gastric chyme through the duodenum again. This can be done more simply by conversion to a Billroth $I$ operation.

To sum up. I am not of the opinion that the early post-cibal or dumping symptoms are sufficiently frequent or severe enough to cause alarm. They can, however, be disturbing in a certain small group of cases. The severity of the disturbance can be minimized by warning the patient that these attacks are likely to arise for a limited space of time. In our own series we found the attacks less common after the gastro-duodenal and antecolic gastro-jejunal anastomosis, and so we favour these operations on that account. If the attacks do develop, it is reasonable to reassure the patient, for the severity of the attacks diminishes with time.

Further surgery should on no account take place less than a year after operation, because of the tendency of the symptoms to abate.

Before operating a second time for post-cibal symptoms there is one piece of advice I would give most earnestly, and it is this. Look up the first notes of the patient-read the letter sent by his doctor when he first came. This may be a revelation. There is an all too facile tendency to attribute to a gastrectomy all the ills that subsequently befall the patient. In two of my very worst so-called post-gastrectomy dumping cases, I studied the earliest symptoms and found that the fatigue, and bloating after meals, palpitations and feelings of weakness were all complained of prior to the gastrectomy-in addition to the ulcer symptoms and only the ulcer symptoms had been cured by 


\section{OPERATIONS FOR 'DUMPING' SyMPTOMS}

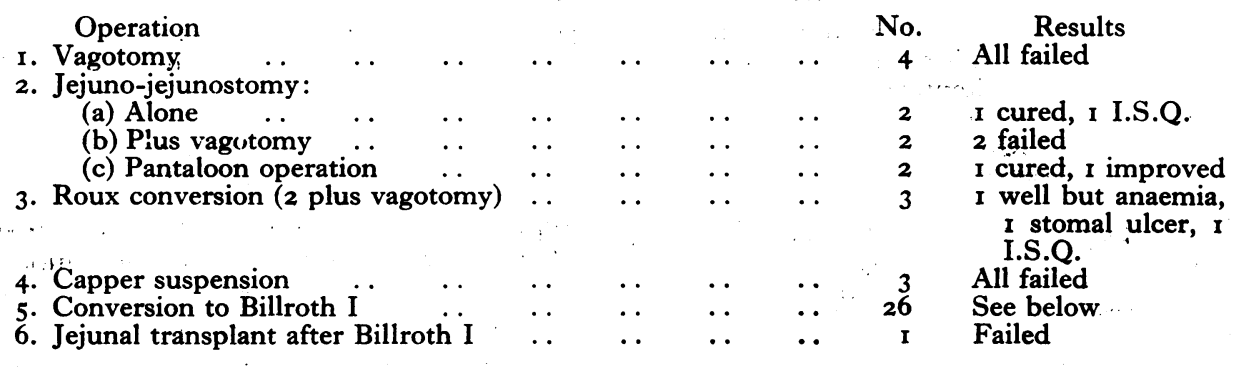

In all these cases the anaemia was microcytie the gastric resection. Needless to say, technical variations in the operation will not relieve such patients. Furthermore, two of my old gastrectomy patients who developed carcinomas were for a time returned to us as cases of post-cibal symptoms. Carcinoma of other organs than the stomach should be considered when old gastrectomy cases lose weight severely or become suddenly anaemic. Of course it is possible for carcinoma to develop in the gastric stump, for B. F. Swynnerton and N. C. Tanner (1953) record that four patients out of 254 developed cancer in the gastric remnant between five and twelve years after gastrectomy for simple gastric ulcer.

Now if it is found that the dumping symptoms are truly consequent on the gastric resection, and particularly if much biliary vomiting or weight loss is complained of, then further surgery can be considered. The procedure we have found most satisfactory is conversion of a gastro jejunal into a gastro-duodenal anastomosis. If the dumping persists after a Billroth I form of anastomosis, then no surgery is advisable unless it can be shown that there is recurrent ulceration, stomal obstruction or a mechanical defect.

\section{Anaemia Following Gastrectomy}

It is well known that iron deficiency anaemia is common in patients with achlorhydria and we cannot expect to reduce the gastric acidity radically without getting diminution of the powers of iron absorption. My friend, Mr. Harold Burge of the West London Hospital has surveyed large numbers of our cases and his own and finds that there is a tendency for the blood haemoglobin percentage to fall with each year following partial gastrectomy. He has kindly placed this Table at my disposal.

\section{Gastrectomy for Simple Peptic Ulcer Male Cases \\ (50 cases examined in each year) Years after Gastrectomy}

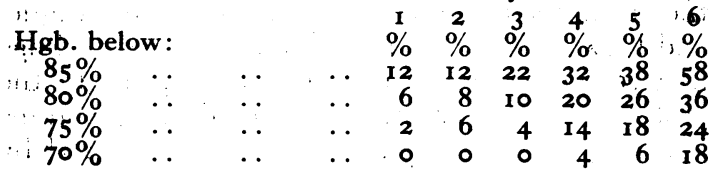
and responded to iron therapy, though it would gradually relapse if iron was discontinued. $\mathrm{M}$ Burge made similar careful examination of a groug of female cases and found the same trend, though as might be expected, it was more exaggeratedo e.g.; at the end of five years 84 per cent. had haemoglobin below 85 per cent.

We advise our gastrectomized patients to tak iron-containing foods and warn them of the symptoms of iron deficiency anaemia. In the follow-up of 6i I of our gastrectomy patients by Craig and Chippendale, 12 were suffering from, of had been treated for a microcytic anaemia, a용 incidence which was not significantly greater thă that among patients without operation.

I have seen only one macrocytic anaetiag following one of our gastrectomies.. This was patient who had had a total gastrectomy, splenţ ectomy and hemi-pancreatectomy for carcinoma $\mathrm{He}$ was very well and had a blood count withip normal limits for six years after operation and the quite suddenly became anaemic, and the anaemia was found to be a macrocytic one.

\section{Weight Loss following Gastrectomy}

The cases of weight loss following gastrectom usually result from diminished intake of foog rather than any deficiency of fat digestion. (Braic and Stammers (195 I).) Thus the comfortable patient usually maintains or gains weight, but there is some post-prandial fullness, dumping biliary regurgitation, pain or stenosis from stomad ulceration, then intake is restricted and the weigh may fall. The treatment of weight loss is to trea any of these causative lesions and to encourage the intake of a high calorie diet. In our afore mentioned series of 61 I gastrectomies it was found that compared with their best or normal weight 244 ( 53 per cent.) had gained weight, I60 (34 pes cent.) had lost up to one stone and 60 (13 per cent.) were more than a stone under weight. The antecolic valved gastro-jejunal type of operatiof gave the greatest gain of weight, but there was not a great deal of difference in the three groupso (57.8 per cent. antecolic 'Polya,' 50 per cent 
Billroth I and 46 per cent. retrocolic 'Polya' gained or maintained weight.)

\section{Biliary and Pancreatic Disease}

Suspicions that gastrectomy increases the incidence of biliary disease rest on very incomplete evidence. I have operated for biliary disease about six times in patients who had had gastrectomies in various parts of the world, but have never found it where there was an assurance that the gall-bladder was previously healthy. We make a note of the state of the gall-bladder in our gastrectomy cases, and biliary disease is not an infrequent finding. It is, of course, most important to make a systematic examination of the abdominal contents before concentrating on the ulcer. It is only too easy to become absorbed with ulcer problems and omit particular examination of the gall-bladder I suspect that it often gets overlooked during gastrectomy.

Pancreatitis occurs occasionally after gastrectomy and in acute afferent loop obstruction the pancreas may be oedematous, the gall-bladder distended and the urinary diastatic index raised. I have operated for acute pancreatitis four times in patients who have had gastrectomies at intervals of between a few days and several years after operation. These are not due to pancreatic trauma and none to the best of my knowledge followed cases of penetration of the pancreas by an ulcer or difficult duodenal dissections. I have also seen chronic pancreatitis with dilated biliary ducts in another old gastrectomy case. All of these patients had had gastro-jejunal stomas. I suspect that defunctioning the duodenum and perhaps altering the mechanics of biliary drainage, slightly increases the chance of developing pancreatitis. Acute or chronic afferent loop obstruction probably increases it still further-possibly by causing dilatation of the biliary and pancreatic ducts and so enabling duodenal juices to enter the pancreas. I have not seen the condition following a Billroth I (gastro-duodenal) gastrectomy, nor thus far in any of our more recent series of short afferent loop gastrectomies. Biliary and pancreatic complications -if they are truly complications of gastrectomy and not merely incidental, require that there should be careful documentation at the time of the original operation in order to confirm and elucidate them.

\section{Pulmonary Tuberculosis and Gastrectomy}

In most large gastrectomy 'follow-ups' a certain number of new cases of pulmonary tuberculosis can be expected to occur. There is some suspicion that after gastrectomy the number of new cases may be higher than would normally be seen. It is known that starvation and sudden weight loss is sometimes associated with diminished resistance to pulmonary tuberculosis. I have pointed out that after gastrectomy, 13 per cent. of the cases drop to more than a stone below their usual weight. We have found it difficult to establish with certainty whether there is an actual increase of pulmonary tuberculosis following gastrectomy. At times we find it necessary to operate for peptic ulcer in the presence of pulmonary tuberculosis, and such operations are entirely justified if the ulcer is causing weight loss and the operation is likely to lead to an increase in weight-as for example in duodenal ulcer stenosis, or penetrating gastric v'lceration.

In a recent review of our gastric ulcer cases it was found that two patients with pulmonary tuberculosis who had a gastrectomy for gastric ulcer were doing well over five years later.

More recently, with the aid of Dr. F. E. Nash, the Director of the Mass X-ray Unit for SouthWest London, we have investigated very carefully the series of 6II consecutive gastrectomies examined by Mr. C. Craig and Dr. Chippendale. Four hundred and three of these patients were mass X-rayed between two and seven years after gastrectomy. Of all these, four had ' radiologically significant lesions, probably tuberculosis,' requiring further investigation. After investigation at chest clinics, only two of these four were classified as having active tuberculosis. This gives a rate of five per thousand, which is exactly the rate of discovery of active tuberculosis in the age group 45 to 59 in members of the general public and factory groups examined by the same Mass X-ray Unit in South-West London. This figure therefore does not suggest any increased risk of tuberculosis. In addition we carefully searched for evidence of deaths due to tuberculosis or sanitorium admissions out of the 6I I group. It was found that two had died of pulmonary tuberculosis and eight had had or were having treatment in a tuberculosis sanatorium. It is extremely difficult to find a similar group with which to compare the latter two figures. We are investigating the matter with statistical aid and hope to report more fully later. We do not think that we shall find any very remarkable increased proneness to tuberculosis, particularly as some had been treated for the disease prior to operation.

\section{Vitamin Deficiences}

This possibility was carefully studied by Dr. Chippendale and Mr. Craig in their follow-up. They found among the 6ir cases followed-up, that eleven cases presented symptoms suggestive of Vitamin B deficiency. Of this number, six complained of paraesthesiae and five of stomatitis or glossitis. It is difficult to know if this is a higher 

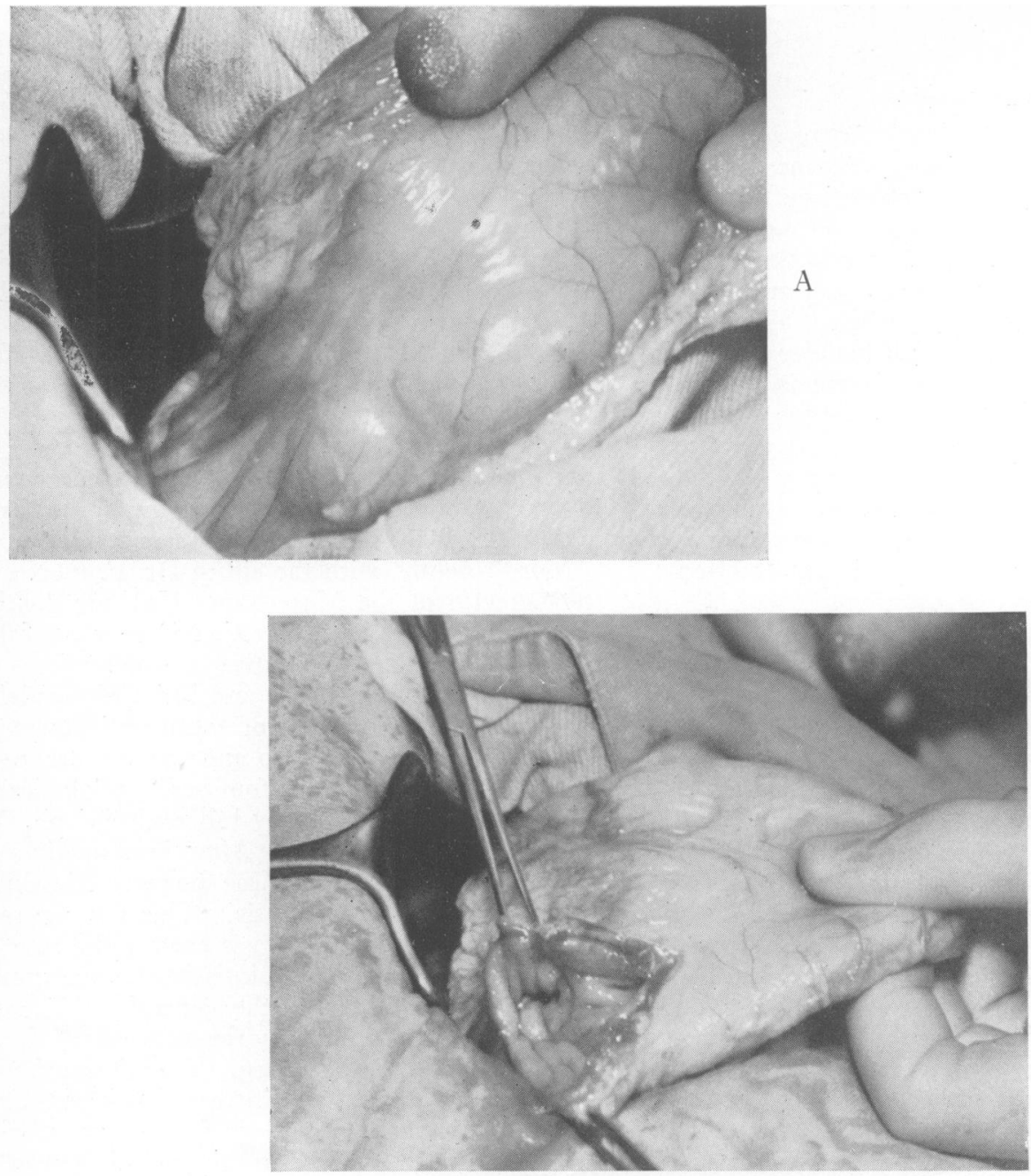

B

Fig. 18.-The Heineke-Mikulicz pyloroplasty. A-The deformity due to duodenal ulceration, note the diverticula between pylorus and the ulcer scar. B-A longitudinal incision through pylorus and scar is pulled out transversely. C-The incision is sutured transversely.

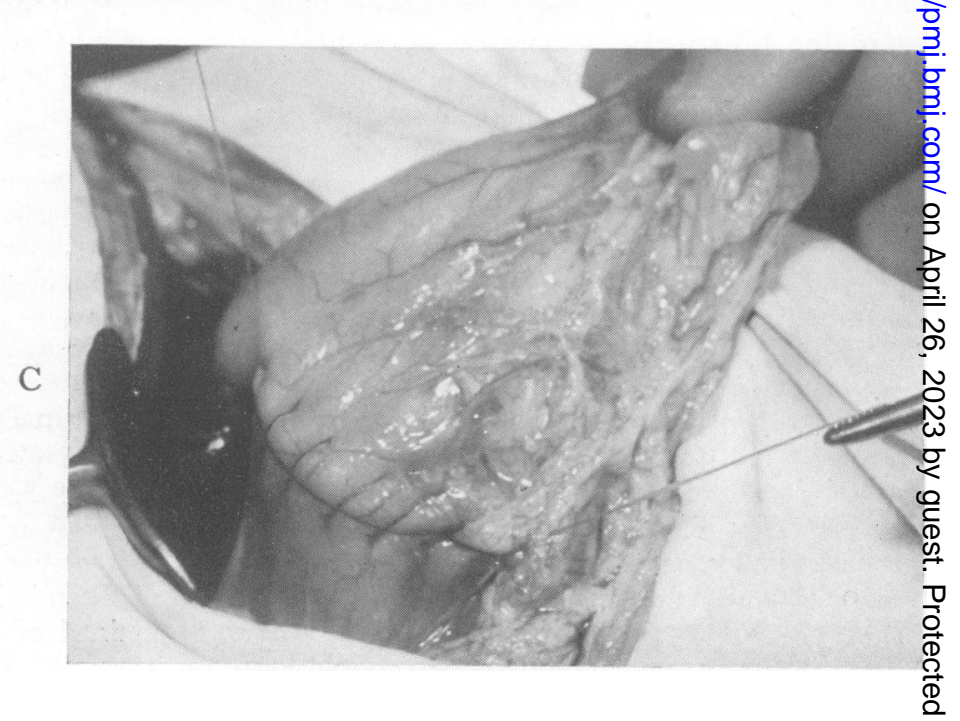


number than might be expected in an examination of $5^{15}$ people in these age groups. The finding is to my mind on a par with that of the iron deficiency anaemia. In order to cure the ulcer we have lowered the hydrochloric acid concentration in the stomach. We know that in the presence of hypoacidity, iron and vitamin absorption may be impaired. It is, therefore, not surprising that a small percentage of these cases will get iron or Vitamin B deficiency. It is wise, I think, to advise the gastrectomized patient to take a slight excess of iron and Vitamin $B$ in the diet, in order to compensate for this deficiency. It is fortunate that the deficiency can be so readily overcome.

\section{Vagotomy for Duodenal Ulcer}

I mentioned in my first lecture that vagotomy is still under trial in the treatment of duodenal ulceration. In I943 I carried out two or three partial vagotomies combined with fundusectomy, but it did not appear to be very effective. In 1947 being convinced that complete vagal section had great potentialities for benefit to the ulcer patient, we felt it our duty to try to assess the operation as rapidly and as scientifically as possible. In order to be sure that any beneficial effects were in fact due to the vagotomy, we decided to use pure vagotomy without accessory operations in a fairly unselected series of duodenal ulcer cases. In cases where there was gross duodenal stenosis, correction of the mechanical defect was imperative and so we added a Heineke Mikulicz pyloroplasty in these cases (Fig. I8a, b and c). Our previous experiences of simple pyloroplasty for duodenal ulcer were enough to persuade us that it was not a curative operation and that any beneficial results from the combination could be safely attributed to the vagotomy.

Following this programme we soon came into trouble, for although those who needed a pyloroplasty did well on the whole, some of those who simply had a vagotomy suffered greatly from gastric retention, foul sulphurous belching and some had diarrhoea. This led to a good deal of personal discomfort and domestic upset to the patients, and it is well known that many surgeons abandoned the vagotomy operation altogether on this account. It appeared to us, however, that this condition which is also seen in cases of obstructive oesophageal or gastric cancer, was due to the combination of hypoacidity with gastric statis. In a way it revealed the effectivity of vagotomy. We decided that one of these factors, obviously the stasis, must be overcome. Consequently, in 1948 we decided that we must abandon simple vagotomy, and thereafter we added a pyloroplasty in all cases, for we found to our surprise that this simple procedure greatly expedited gastric evacuation, even in those without the slightest duodenal narrowing. This removed most of the trouble. A Finney type of pyloroplasty was necessary in two children whose deformity was considered to be too extreme for the Heineke Mikulicz operation. We used gastrojejunostomy in a few cases where the duodenum was extensively damaged, though we avoided it as a routine, because although it may well eventually prove to be the most satisfactory addition to vagotomy, it would have clouded the issue as it is itself curative of the duodenal ulcer.

\section{Technique of Vagotomy}

The results of vagotomy depend on a scrupulous technique. The transthoracic approach is unsuitable because the nature of the lesion cannot be confirmed, and the so-called drainage operation, the pyloroplasty, cannot be added. We use a high abdominal approach, sometimes removing the xiphisternum and then reflect the left lobe of the liver to the right, after dividing the left triangular ligament. The oesophagus is exposed by a transverse incision through the two distinct layers over it, the peritoneum and the phreno-oesophageal ligament. In order to steady the oesophagus it is usual to put a tractor tape round it. I gave up this practice because I feared it might increase the liability to cardiospasm and because it obscures the lower vagal branches. Instead I pass a rubber band through the lesser omentum into, and then through the roof of the lesser sac over the fundus of the stomach to the left of the oesophagus (Fig. 19). On drawing this down the branches of the anterior vagus nerve to the body and lesser curve of the stomach and to the liver can be easily dissected and the branch of the posterior vagus to the coeliac artery can be readily palpated. The nerves are cut well down on the stomach after they have divided into branches, and also as high as can be reached through the oesophageal hiatus. After carefully searching for any accessory vagus fibres, the opening in the phreno-oesophageal ligament is closed to prevent subsequent hiatus herniation. Following this the pyloroplasty is carried out.

Like many others we made several early follows-up which showed reasonably satisfactory results, but the results were confusing because of the number of recent cases. I really do not think we should draw conclusions on anything less than a five year follow-up, and that is why, when I am asked "What is the place of vagotomy in the treatment of duodenal ulcer ?' I have to answer that I do not know. However, the reply to the question is slowly emerging. On the fifth anniversary of their operation, all our vagotomy 


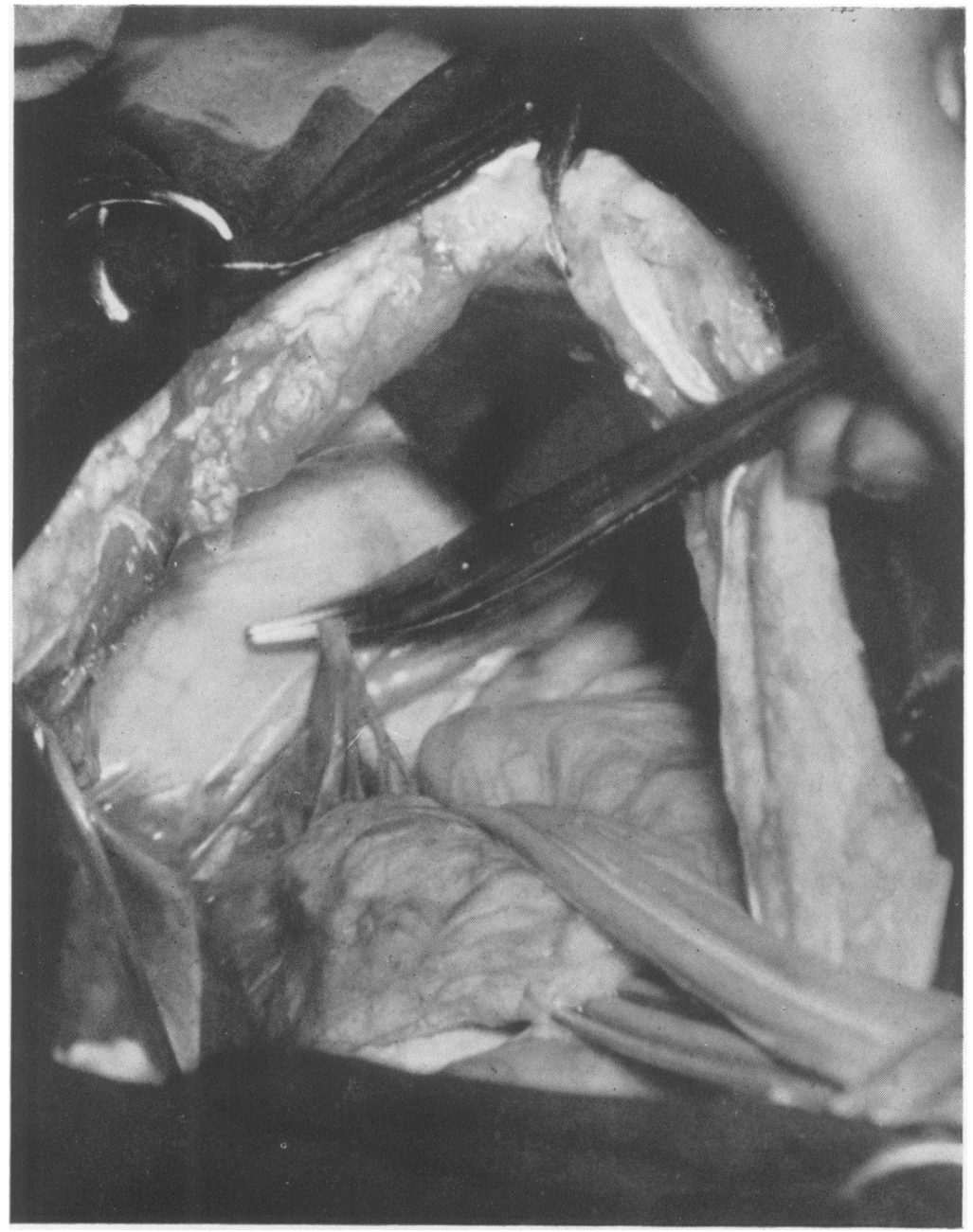

Fig. 19.-The author's method of traction over the gastric fundus-which allows good exposure of the branches of the vagus nerve.

cases come to the hospital for careful assessment by Dr. Brian Swynnerton, our Weir Research Assistant. The results to date or prior to any secondary operation, containing as they do mainly our early pure vagotomy cases, do little more than confirm our dissatisfaction with that operation. (The Visick classification is used.)

\section{TABLE I}

Simple Vagotomy for Duodenal Ulcer (No secondary operations)

Number of cases

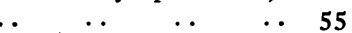

Died since (not of ulcer) $\quad \ldots \quad \ldots r \mid 2$

$\begin{array}{lllllll}\text { Very satisfactory } & \ldots & \ldots & \ldots & \ldots & 19 & 35.8 \%\end{array}$

Minor symptoms not controlled by care

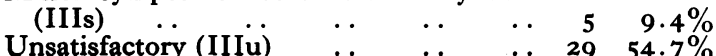

The causes of the poor results were as follows:

\section{TABLE IA}

$\begin{array}{lllllll}\text { Gastric retention } & \ldots & \ldots & \ldots & \ldots & \ldots & \text { 理 }\end{array}$

Active recurrent duodenal ulceration $\quad$. $\quad \ldots \quad$.

Ulcer-type pain, scar only at later operation $\quad . \quad$ m

$\begin{array}{lllllll}\text { Later gastric ulcer } & \ldots & \ldots & \ldots & \ldots & \ldots & \text { 工 }\end{array}$

$\begin{array}{lllllll}\text { Miscellaneous } & \ldots & \ldots & \ldots & \ldots & \ldots & \text { N }\end{array}$

Note.-Of the 29 unsatisfactory cases, 27 have had subsequent operations ( 13 pyloroplasty, 7 gastre jejunostomy and in partial gastrectomy).

The final state of the 53 surviving simpie vagotomies with their various drainage and re section operations is as follows: 
TABLE 2

Original simple vagotomy cases +31 further operations on 27 cases. Five year follow-up

Very satisfactory (Gdes. I and II) $28 \quad 52.8 \%$

Minor symptoms not controllable by care (IIIs) . .

Troublesome symptoms (IIIIu and IV)

Too soon since last operation to assess
$\left.\begin{array}{ll}28 & 52.8 \% \\ 15 & 28.3 \%\end{array}\right\} 8$ r. I
$5 \quad 9.4 \%$
$5 \quad 9.4 \%$

Total $\ldots \quad \ldots \quad \ldots 53$

It has been noted by many workers that the final result is much better when vagotomy and the drainage operation are done primarily than when a drainage operation is done after the vagotomy has produced severe and prolonged disability from stasis. This is confirmed by our own series, in which four secondary gastro-jejunostomies for post-vagotomy stasis all gave poor five year results, two as a result of stomal ulceration.

\section{Vagotomy and Pyloroplasty}

This combination has been our main operation and from its late results we hope to gain a good deal of information on vagotomy. However, only four cases in which both procedures were done coincidentally have reached the five year mark. Three are very satisfactory and one has minor troublesome symptoms.

\section{Vagotomy and Gastro-Jejunostomy}

Fifteen patients including one operation death. Results in the remaining 14 :

\section{TABLE 3}

Vagotomy and Coincident Gastro-Jejunostomy. Five year result

$\begin{array}{lllll}\text { Very satisfactory (I and II) .. } & \ldots & \ldots & \ldots & \text { I I }\end{array}$

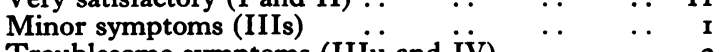

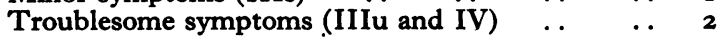

One of those with troublesome symptoms had developed a stomal ulcer and is now very satisfied following a gastrectomy. The other is menopausal, but as she attributes all her symptoms to the operation she must be adjudged a poor result.

$I$ have not quoted the results of many other surgeons because nearly all report a mixture of recent and older cases. However, reports of four years and upwards generally show about an 85 per cent. satisfaction rate for vagotomy plus gastrojejunostomy (Pollard et alii, 1952).

\section{Side Effects of Vagotomy}

What are the untoward effects which lead to poor results? Naturally a small proportion are due to bad selection-severe functional overlay, menopausal symptoms, mental disease, associated incapacitating diseases-tuberculosis, bronchitis, etc. - these are found in any medical or surgical follow-up.

Belching, vomiting and epigastric cramps are mainly due to gastric retention and have been largely overcome by the routine addition of a 'drainage ' operation. Severe diarrhoea has been relieved by correction of gastric stasis. However, a certain amount of looseness of the bowelusually in the early morning may occur, but does not trouble the patient much and is controllable by intestinal antiseptics.

Cardiospasm has always been transitory, though I did have to remove an inspissated meat bolus from the lower oesophagus of one patient eighteen months and again five years after vagotomy.

Hypoglycaemia-like attacks are troublesome in a small percentage of cases but tend to be transitory and to improve when gastric stasis is corrected.

I doubt if recurrent gastric ulceration is really due to vagotomy. The two cases we have seen may well be small ulcers present at the first operation, which continued to progress despite vagotomy (neither had been gastroscoped). I do not think there is any evidence that vagotomy will be of any great help in cases of gastric ulceration.

To sum up we can say that simple vagotomy for duodenal ulcer should be abandoned because of its severe retention symptoms. We can say that secondary operations after severe retention symptoms are established improve the situation but will only completely relieve about half of them. The best results will be obtained when vagotomy and a 'drainage operation' are done at the same time and on our present small figures, between 75 per cent. to 85 per cent. prove satisfactory at the end of five years. I do not feel prepared to make a personal opinion on the operation until I have studied far more of our cases on the fifth anniversary of their operation. It is too important a matter in which to hazard an opinion, when patience will reward us with a clearer view of the truth.

(The third lecture of this series will be published in the next number of this journal.) 